\title{
The Application of Salutogenesis in Cities and Towns
}

\author{
Ruca Maass, Monica Lillefjell, and Geir Arild Espnes
}

\section{Introduction}

This chapter casts light on how cities can facilitate good health through urban planning, design and organization, and collaboration across sectors. The way we organize cities is one aspect of the social determinants of health and can manifest or balance several aspects of social injustice. The focus of this chapter is on how Health in all policies (HiAP) can be implemented at the city level, and in which ways the WHO's Healthy City Network contributes to this work.

The chapter focuses on matters of planning and maintaining infrastructure, including transportation systems, green spaces and walkability, as well as matters of environmental justice across cities. We take a closer look at the evaluations of HiAP, as well as the Healthy Cities approach, and to what degree they facilitate long-lasting cross-sector collaboration. We discuss whether and how a salutogenic orientation can link places and environmental resources to health outcomes and explore the implications of this approach for salutogenic practice and salutogenesis research.

\section{Key Concepts and Cultural, Practice, and Research Contexts}

The WHO focuses on creating settings which allow for the experience and development of good health: "Health is created and lived by people within the settings of their

R. Maass $(\bowtie) \cdot$ M. Lillefjell

Department of Health Science, Center for Health Promotion Research, Norwegian University of Science and Technology (NTNU),

Trondheim, Norway

e-mail: Ruca.e.maass@ntnu.no; monica.lillefjell@ntnu.no

G.A. Espnes

Department of Social Work and Health Science, NTNU Center for

Health Promotion Research, Norwegian University of Science and

Technology, Trondheim, Norway

e-mail: geirae@svt.ntnu.no everyday life; where they learn, work, play and love" (WHO, 1986). Health and health equity in all local policies are the overarching theme, recognizing that a population's health is not merely a product of health sector programs, but is also largely determined by policies and actions beyond the health sector.

To create cities which allow inhabitants to lead active, healthy lives and to experience well-being and quality of life is right at the core of this goal. Planning processes tend to focus on enabling "active living" in the residential context of individuals. This includes enhancing possibilities for social participation and physical activity. The main objective is to "make people active participants in their own life, empowered, understanding what is important for health and (...) be able to use the resources" (Lindström \& Eriksson, 2011).

This chapter casts light on factors and processes within cities and urban planning that have been linked to favourable health outcomes. It includes research with a clear perspective towards the positive aspects of life (resources, health, well-being, quality of life). Cities are understood as complex systems, where physical, social, and organizational aspects all interact. We apply a town planning perspective, with a focus on the directly influenceable aspects of the setting, namely the physical environmental and organizational/public policy issues. In addition to health literature, we also include research from the fields of town planning and geography.

\section{Salutogenesis and the Urban Environment}

Within the salutogenic orientation, the focus is on the upstream conditions for experiencing good health and quality of life: instead of trying to reduce damage in areas or in populations at risk, including health in the planning processes of urban environments can improve living conditions along the whole social gradient of health (Lindström \& 
Eriksson, 2011). The concept of healthy cities includes a variety of aspects linked to people's possibility of experiencing and developing good health in the urban environment. Cities are complex systems and include a variety of smaller micro-systems such as neighbourhoods, workplaces, and schools. The city itself is experienced on the basis of what happens within and between these micro-systems. Both the micro-systems and the larger system of the city in which they are embedded include aspects of people, place, nature and the built environment, and the broader social and political context.

Even though a growing body of research attempts to explore the relationships between urban living environment and health, and a number of voices have called for a guiding theory to systematize this knowledge, few studies explicitly apply the theory of salutogenesis. Applying salutogenesis to the city context allows us to include resources at various levels of experience (such as streetlights and sense of place) and link them to health outcomes through the concepts of generalized resistance resources and sense of coherence: environmental resources can be internalized and become generalized resistance resources, thereby strengthening sense of coherence (Antonovksy, 1993). Bull, Mittelmark, and Kanyeka (2013) put it this way:

By mobilizing the capacity and assets of people and places, local development initiatives will make sense logically in the local context (comprehensibility), (...) practically realistic (manageability) and they will be motivating because they are meaningful, based on involvement in decision-making processes (meaningfulness). (p. 171)

The experience of good health depends on the interplay between environmental resources and individual sense of coherence. If and how resources are used may partly depend on sense of coherence: while a stronger sense of coherence might allow for health-promoting use of resources even in a resource-poor environment, easily identifiable and useable resources might be crucial for engagement in health-promoting behaviour for people with a weaker sense of coherence. Merely placing resources into a context might primarily benefit people with a strong sense of coherence, and thereby could even widen the gap in health (Cohen et al., 2012).

However, high satisfaction with the quality of resources might contribute to balance out the drawbacks of a weaker sense of coherence (Maass, Lindström, \& Lillefjell, 2014). Focusing on developing resources which are perceived as adequate by deprived groups might therefore be a beneficial strategy to reduce health inequality (Maass et al., 2014).

Thus, salutogenesis offers a theoretical framework which allows us to link environmental resources to health outcomes and to the development of a strong sense of coherence. Moreover, it also calls for us to focus on the processes involved in the establishment and maintenance of resources.
This thought is right at the heart of the HiAP approach; systematic focus on health, the health impacts of policy decisions, and the development of public policies on a global, national, and local level. Applying HiAP involves identifying health-related policies and developments across sectors, assessing the impact of decisions, and advocating for positive change. The focus is on the broad social and environmental determinants of health, and the goal is to create healthy environments and achieve environmental and social justice. One of the core features of HiAP is to encourage collaboration and build long-lasting networks between sectors, decision-makers, stakeholders, and the public, and reduce health inequalities (Olilla, Baum, \& Pena, 2013; Ståhl, Wismar, Ollila, Lahtinen, \& Leppo, 2006).

\section{Environmental Justice}

Inequalities across and within cities are one aspect of social injustice in health (WHO, 2007, 2012a, 2012b). Health inequalities that are consequences of environmental inequalities are part of the so-called environmental justice domain (WHO, 2012b). Environmental justice consists of two dimensions: distributional and procedural justice (Kruize, Droomers, van Kamp, \& Ruijsbroek, 2014).

Distributional justice refers to the spatial distribution of environmental risks and resources. Most research in this domain has focused on risk factors that are distributed unequally across cities and neighbourhoods. However, the neighbourhood context essentially also involves the availability of, and access to, health-relevant resources. For example, in neighbourhoods with lower socioeconomic status, there are fewer free facilities for physical activity than in high socioeconomic status neighbourhoods, whereas the number of paid facilities does not differ (Li, Fisher, Brownson, \& Bosworth, 2005).

Procedural justice refers to individuals' or communities' opportunities to take part in and influence decisions and planning processes, which, in turn, create the environmental conditions for daily living. Procedural justice might thereby not only benefit the involved individuals or groups in terms of well-being and empowerment, it can also contribute to creating environments that fit the needs and wishes of inhabitants (Kruize et al., 2014). The Healthy City approach aims at reducing both distributional and procedural injustice within cities.

\section{The Healthy City Network}

The Healthy Cities project of the World Health Organization (WHO) was established in 1987 in the European Region as a strategy for implementing Health for All at the local levels 
of government (WHO, 2012a). The core aim of the project is to improve health by addressing the determinants of health and the principles of Health for All and sustainable development, by providing governance and partner-based planning for health. Today, it is recognized as a global public health movement both at the local level and within the WHO European region. Healthy Cities give explicit political commitment to improving their citizens' health. By offering a coherent set of enduring qualities, elements, and goals, they acknowledge major health challenges and the economic, physical, and social factors that influence these challenges. An important aspect of the WHO Healthy Cities project is that, in line with salutogenic thinking, it focuses on the community as a whole, with its strengths and barriers, rather than on single issues or diseases.

This approach integrates the concepts of people and place and has clear intentions to promote health across the lifespan, to improve social determinants of health, and to improve conditions for daily life (WHO, 2007, 2012a, $2012 b)$. This includes income and access to resources, training, people and places, transport, climate changes and sustainability, with individuals and communities being empowered. Places can be perceived as enabling by offering social, material, and affective resources (Hand, Law, McColl, Hanna, \& Elliott, 2012). In their review of the Healthy Cities initiative, Barton and Grant (2013) identified 12 major topics through which cities can increase the health of their inhabitants, located on different levels of the citysystem. In this chapter, the focus will be on the topics of overall planning and urban form, transport and accessibility, green spaces, recreation and physical activity, infrastructure, urban design and environment quality, and coordination and politics.

Context is important: something that can be a resource in one neighbourhood or some social groups, might not work as such in another neighbourhood or for other social groups. Culture, gender, and age might influence perceptions and use of resources (Angotti, 2013; Bai, Stanis, Kaczynski, \& Besenyi, 2013; Krenichyn, 2004). For example, children's active lifestyle seems to be dependent on an overall "activity-friendly" context, which includes fewer parking spaces (de Vries, Bakker, van Mechelen, \& Hopman-Rock, 2007). Adolescents are attracted to proximate low-cost, well-maintained facilities that offer preferred activities (Ries et al., 2008). For older adults, proximate locations and accessibility to key resources were linked to social participation (Richard et al., 2013). The relative importance of the residential area and its resources differs across groups, and might partly be dependent on having access to other important societal arenas, like the workplace (Maass et al., 2014). Additionally, different factors promote heath in healthy and in less healthy people (Fuller, Stewart Williams, \& Byles, 2010).

This highlights the importance of grounding interventions in the local setting and drawing on local resources and stakeholders, and include contextual matters. For example, population density has been linked to both positive and negative health outcomes; reflecting that population density in an urban context is usually lower in high socioeconomic status neighbourhoods. However, areas that have been described as highly resilient in spite of material deprivation were found to be characterized by being densely populated and situated near, but not at, the city centre (Pearson, Pearce, \& Kingham, 2013). Land-use mix has been linked to physical activity, among other factors, through the variety of destinations for walking (Gidlow, Cochrane, Davey, Smith, \& Fairburn, 2010; Millward, Spinney, \& Scott, 2013).

\section{Infrastructure, Transportation, and Active Travelling}

Infrastructure influences health and well-being through the distribution of resources, opportunities for activity, and social meeting places that can facilitate social connectedness, possibilities for outdoor recreational activity, and active travel (Lenzi, Vieno, Santinello, \& Perkins, 2013; Shimura, Sugiyama, Winkler, \& Owen, 2012). For example, levels of satisfaction with a residential area are linked to how long it takes to travel to important locations, rather than mere distance (Delmelle, Haslauer, \& Prinz, 2013). Safe conditions for active travel can enhance physical activity (Fuller et al., 2010; Wen, Kite, Merom, \& Rissel, 2009). Different groups have varying needs in regard to transport and communication around transport (Raerino, Macmillan, \& Jones, 2013). Especially for minors, the elderly and the physically impaired, the availability, and accessibility of transportation can have a major impact on the possibilities for independent living (Raerino et al., 2013). Even minor disabilities can heavily influence possibilities for active living and independence, and thus the need for proximate, accessible, and inclusive infrastructure and available public transport (Levasseur et al., 2011; Norgate, 2012; Wen et al., 2009). Planning and design of transportation systems and outdoor spaces in line with the principles of Universal Design can enhance the accessibility of resources for these groups and promote active travelling for a wider population.

Active travelling, such as walking and biking for transport and leisure, is an important aspect of a healthy city. The "walkability" of a city district refers to its environmental and social aspects that influence walking. High walkability of a district has been shown to increase walking among its 
inhabitants and has been linked to positive health outcomes, both directly and indirectly, through increase in physical activity and social contacts (de Nazelle et al., 2011; Hankey, Marshall, \& Brauer, 2012; Leyden, 2003). Children who are allowed to walk on their own near where they live tend to play more outdoors, and environments that promote greater independent mobility increase physical activity in children (Kuo et al., 2009; Wen et al., 2009). For older people, frequent walking (and perceived accessibility to key resources) is positively associated with social participation (Richard et al., 2013). High walkability of a district can motivate increased physical activity among both healthy and less-healthy older adults (Fuller et al., 2010; Shimura et al., 2012).

Moreover, the perceived friendliness and pleasantness of a place — the aesthetics — can influence behaviour and social relations: for example, walking in the neighbourhood, stopping and chatting with your neighbour, or letting your children go out and play. Aesthetics also play an important role for walking for recreation (Kaczynski, 2010). To improve visual appeal is one goal in "active living" urban planning (Faskunger, 2013).

However, the health benefits of walking are partly dependent on other factors, such as air pollution (Hankey et al., 2012). Again, aspects of environmental justice become visible in this context: the so-called sweet spots-characterized by high walkability and low air pollution-are almost exclusively situated in high socioeconomic status districts located near but not at the city centre (Marshall, Brauer, \& Frank, 2009).

\section{Green spaces, Recreation, and Physical Activity}

Proximity to green spaces, including everything from the surrounding landscape to urban parks and gardens, might play an important role in health promotion: associations between distance to a green space and health as well as health-related quality of life are found repeatedly, independent of which measure of green space is applied (Mitchell, Astell-Burt, \& Richardson, 2011; Stigsdotter et al., 2010). Kyttä, Broberg, and Kahila (2012) even found that green space was the only urban variable directly connected to children's perceived health. Relationships between green space and health are influenced by gender, ethnicity, socioeconomic status, living context, green space type, and climate (Cohen et al., 2012; Lachowycz \& Jones, 2013).

Matters of quality can become prominent in some settings or for some social groups (Bai et al., 2013). For example, women seemed to be more dependent on perceptions of safety and the presence of others for engaging in physical activity in their park (Krenichyn, 2004). Accessibility of green spaces is one aspect through which environmental injustice becomes visible across cities, with high socioeconomic status neighbourhoods usually being closer to and including more green spaces compared to poorer areas (Angotti, 2013; Moseley, Marzano, Chetcuti, \& Watts, 2013).

Additionally, there seem to be differences in the degree to which users perceive their proximate green spaces as matching their needs, with a special emphasis on cultural and age-dependent aspects (Angotti, 2013). Thus, mere physical proximity might not give a realistic picture of the accessibility of green spaces (Moseley et al., 2013).

In addition to facilitating physical activity, research suggests there are psychological benefits deriving directly from contact with nature: attention restoration, stress reduction, and positive emotions (Abraham, Sommerhalder, \& Abel, 2010; Lachowycz \& Jones, 2013). Moreover, green spaces can enhance social well-being through social integration, participation, and engagement within the context (Abraham et al., 2010). In particular, access to waterways or coastal lines, "urban blue", seems to be linked to wellbeing, engagement in recreational activities, stress reduction, and the development of a strong attachment to the place (Cox, Johnstone, \& Robinson, 2006).

\section{Sense of Place}

Attachment and feelings of belonging to a place play an important role in experiencing quality of life and positive identity (Nogueira, 2009; Tartaglia, 2013). "Sense of place" has become a popular public health construct, even if there is little empirical evidence on how to achieve it, and its role in health promotion (Frumkin, 2003). Sense of place has also been labelled as a motivator for physical activity, both among healthy and less healthy older adults (Fuller et al., 2010). While some research suggests that sense of place is highest in high socioeconomic status neighbourhoods, associations between sense of place and self-perceived mental health do not seem to be dependent on neighbourhood socioeconomic level (Williams \& Kitchen, 2012).

\section{Links Between Environmental Resources, Place, and Salutogenesis}

As mentioned above, a number of resources in the city context have been linked to favourable health outcomes. Mostly, health benefits are explained by enhanced physical activity, social and local connectedness, and/or reduced health inequalities. There are few studies examining the links between city resources, sense of coherence, and health outcomes. Emerging evidence suggests that the development of a strong sense of coherence might be dependent on 
processes linked to planning, establishment, and maintenance, as well as perceived quality of resources (Bull et al., 2013; Maass et al., 2014). This is linked to the context-dependence of resources.

\section{Research on Interventions}

While a growing body of evidence links various characteristics of cities to positive health outcomes, planning, implementing, and evaluating interventions in this area is challenging. As cities are complex systems with many interrelated factors, interventions might work in different ways than expected. A number of evaluations of HiAP, the Healthy City Network, and related projects nevertheless give insight for integrating a positive health approach into city planning and administration (Olilla et al., 2013). A sustainable implementation of HiAP is dependent on strong leadership and advocacy, and political will to implement these strategies on a local as well as on a higher level of organization. Yet, over-dependence on local or individual knowledge of health determinants could lead to fragmented efforts and assessments and limited understanding of the broader environmental- and health impacts of particular projects (Dora, Pfeiffer, \& Racioppi, 2013).

Development and increased use of strategic environmental and health impact assessments on a variety of decisions and policies could be described as one important step towards implementing a HiAP approach (Winkler et al., 2013). Moreover, successful policy implementation was dependent on public support. Including democratic processes in decision-making could increase sustainability and long-term effects, and simultaneously ensure legitimacy (Marmot \& Allen, 2013).

\section{Evaluations of the Healthy City Network}

Evaluations of the Healthy City Project across countries have used a variety of measurements and indicators, mainly reflecting the different starting points of cities in high- vs. middle- and low-income countries. Whereas cities in low-income countries could still struggle with providing basic infrastructure like adequate waste disposal and access to clean water, cities in richer countries were able to focus on building networks and establishing inter-sector collaborations (Harpham, Burton, \& Blue, 2001). Overall, evaluations reveal that success is highly dependent on political and material support for the ideas and principles of the Healthy City (Donchin, Shemesh, Horowitz, \& Daoud, 2006). Aronson, Norton, and Kegler (2007) found that conflicting views regarding the importance of intervention on social and living conditions, versus intervention on individuals' lifestyle, were reduced through implementing a healthy cities approach. In contrast, Boonekamp, Colomer, Tomas, and Nunez (1999) found that health programs developed in the wake of the Healthy City Project still focused on personal and individual changes, rather than structural issues. Since then, Kegler, Painter, Twiss, Aronson, and Norton (2009) claimed that the Healthy City Project was helpful in developing a broad-based coalition of residents and community sectors and facilitated community participation. In their evaluation of the project in developing countries, Harpham et al. (2001) found clear differences as to the degree to which awareness could be raised, with two cities adopting a clear settings approach. They also found that the projects mobilized considerable resources and improved inter-sector collaboration.

The role of individual project ambassadors and coordinators and their capacity to facilitate engagement was examined in several evaluations (e.g., Donchin et al., 2006; Harpham et al., 2001). One of the major challenges identified was a lack of resources following the Project, as well as the need to develop overarching evaluation systems and theories to integrate knowledge and develop interventions based on evidence (Rychetnik et al. 2012; Pluemer, Kennedy, \& Trojan, 2010). Another major challenge was to establish collaborations between different sectors which could last over time (Harpham et al., 2001; Pluemer et al., 2010). The pressing need to establish such cooperation can be illustrated by describing some of the features and processes which are necessary to achieve high walkability.

\section{Walkability: An Example of the Need for Cross-Sectorial Collaboration Over Time}

Highly walkable city districts are characterized by high street connectivity, high density, traffic safety, and varied land-use mix (Cerini, Saelens, Sallis, \& Frank, 2006; Saelens, Sallis, \& Frank, 2003; Wilson et al., 2011). Factors that increase safety in terms of both traffic and crime, such as adequate street lights, broad and connected sidewalks, and matters of over-viewing the scenery can be important determinants of walkability especially for seniors (Cerini et al., 2006; Li et al., 2005; Shimura et al., 2012; Wilson et al., 2011). Moreover, as most walks are made to non-home locations, a variety of destinations seems to facilitate walking. Access to recreational facilities, restaurants and bars, grocery stores, and cultural sites within $1000 \mathrm{~m}$ can create a "neighbourhood of opportunity" (Millward et al., 2013).

Among seniors, destinations that facilitate social interaction—restaurants, churches, etc.—and provide opportunities 
for incidental social contact were the strongest predictors of walking (Nathan et al., 2012). As orientation skills can decrease with age, the distinctiveness of places becomes crucial: landmarks and distinctive buildings seemed to be more important for orientation than signage (Philips, Walford, Hockey, Foreman, \& Lewis, 2012). The urban living environment can also be used directly to facilitate engagement and physical activity in the residential context. For example, Ferney, Marshall, Eakin, and Owen (2009) found that giving detailed information about the neighbourhood and the local context increased walking more than did information on the benefits of walking, and the effect of the intervention lasted longer (Ferney et al., 2009). To achieve high walkability, it is not only crucial to include town planners and health workers, but also to incorporate thoughts about health and health promotion into regulation plans, stimulate cultural and commercial activity, and ensure good maintenance.

\section{Procedural Environmental Justice and Inclusive Planning at the Local Level}

Projects that include citizens in the planning and creation of areas and resources often find that the created places are used more frequently, and generate higher levels of satisfaction among their users, compared to top-down projects. This is consistent with the principle that projects and decisions gain legitimacy by applying democratic processes in their planning and implementation (Marmot \& Allen, 2013). Participation in planning processes seems to improve wellbeing, increase social capital, expand social networks, and promote empowerment for the involved individuals and communities (Semenza, 2003; Semenza \& March, 2009; Semenza, March, \& Bontempo, 2006; Twiss et al., 2003).

Despite being resource intensive, isolated programs and interventions have little impact over time. What impact they have seems to be dependent on their ability to involve community partners and stakeholders and facilitate engagement among inhabitants, and offers possibilities for learning and skill-building (Claus, Dessauer, \& Brennan, 2012; Twiss et al., 2003). Interventions highlight the importance of processes through which resources are developed. Procedural environmental justice is highly influenced by power distributions on a larger scale: people with more resources usually have better access to the planning processes, as well as important societal information channels such as media. Developing local procedures which include various groups in the decision-making processes is one important aspect of developing and implementing sustainable healthy policies (Marmot \& Allen, 2013).
Evaluations of interventions in line with the Healthy City Network's principles highlight the importance of healthpromoting processes on a broad level, rather than focusing on singular resources (Angotti, 2013; Barton \& Grant, 2013; Boonekamp et al., 1999):

- City governments should work with a wide range of stakeholders to build a political alliance for urban health. In particular, urban planners and public health workers should communicate with each other.

- Attention to health inequalities within urban areas should be a key focus when planning the urban environment, necessitating community representation in policy making and planning.

- Action needs to be taken on an urban scale to create and maintain the urban advantage in health outcomes through changes to the urban environment, providing a new focus for urban planning policies.

- Policy makers at national and urban levels would benefit from undertaking a complexity analysis to understand the many overlapping relations which affect urban health outcomes. Policy makers should be alert to the unintended consequences of their policies.

- Progress towards effective action on urban health will be best achieved through local experimentation on a range of projects, supported by the assessment of their practices and decision-making processes by practitioners. Such efforts should include practitioners and communities in an active dialogue and mutual learning.

- A focus on developing health-promoting and empowering processes for the creation and maintenance of public spaces might be a more beneficial approach to the creation of healthy cities, than a focus on isolated aspects and resources.

\section{Discussion}

In line with salutogenic thinking, a growing body of research is looking at how the design and maintenance of cities affects the positive side of health and well-being. Moreover, focus on the upstream indicators (planning processes, HiAP, looking at "the whole gradient" rather than focusing only on deprived groups/places) reflects a salutogenic way of focusing on improvement of the general conditions for active, healthy living. Health is experienced as a dynamic interplay between personal variables and contextual factors. Additionally, cities have to be understood as organic systems, where each part affects every other part. All this is reflected in the challenges faced by the Healthy City Network, particularly in the difficulties of developing universal strategies and 
methods to implement and evaluate the goals of the Network.

On a more specific level, a few studies have linked individual sense of coherence to the presence and quality of resources, as well as the degree of involvement in planning settings and implementing changes. This chapter highlights the context-dependence of resources: what constitutes a resource can differ between places and between people. Research suggests interactions between the perception and use of environmental resources, sense of coherence, and health outcomes. The health-promoting and empowering effects of resources seem to be dependent on quality as well as matters of participatory planning and implementation. This highlights the importance of public policy, from a global to a local level: "Policy frameworks are used to construct the coherence needed to form healthy societies" (Lindström \& Eriksson, 2011). Additionally, resources can be found at different levels of experience-from the very specific level, such as street lights and sidewalks, to more complex and abstract levels, such as sense of place.

\section{Implications for Salutogenesis Practice}

The complexity of the city system calls for a focus on interand cross-sectorial collaboration. Who should be involved in the development, design, and maintenance of facilities? The example of walkability highlights the interplay between various factors, involving a variety of agents. The health-promoting effect of walkable ways, for example, might be sabotaged by bad maintenance of lights and renovation, changes in the number and quality of destinations (such as closing shops in the city centre), social climate or decisions made at higher levels, such as land use regulations (Rychetnik et al., 2012). Overcoming the barriers between sectors and developing inclusive processes across sectors highlight the importance of including health considerations in all policies (Olilla et al., 2013; Ståhl et al., 2006). Moreover, the importance of these processes calls for a focus on implementation: How can planning be put to action? More experience in this area is needed from various contexts.

Further, it might be beneficial to aim at strengthening sense of coherence and improving conditions for good health, instead of focusing on health-promoting behaviour. Developing strategies and gathering more knowledge on how environments and environmental processes can enhance comprehensibility, manageability, and meaningfulness of cities might prove to be a beneficial strategy for practice. Focusing on improving environmental and personal conditions for health might also contribute to balancing inequalities in health by allowing people to make better use of environmental resources.

\section{Implications for Salutogenesis Research}

The majority of research in this field focuses on the planning side, while less is known about the process of implementation, and to what degree healthy city interventions really improve health outcomes. Consequently, researchers have called for developing tools, methods, and instruments for implementation and evaluation of the impacts of healthy urban planning.

Using salutogenesis as a guiding theory to describe how health can be promoted in the city context turns the focus towards an internalization process: how does an environmental resource become a resistance resource? More knowledge is needed in order to learn more about internalization, and how it can be facilitated through the living environment. Likewise, the question of when and how an urban feature can become a resource in a local setting seems to be influenced by the degree of citizen involvement in the planning, design, and administration of the feature. Is it possible that being involved in these processes is beneficial for internalization, thereby enhancing health? A closer look at the concept of generalized resistance resources-what characterizes them, what distinguishes them from other concepts, and how they are put to use - might be a beneficial approach for exploring the internalization process and how it is influenced by environmental issues. Can we define conditions for, and qualities within resources that enhance their "internalizability"? The Healthy City setting represents a complex setting and includes people throughout their life courses. Thus, it might offer a number of opportunities for learning more about the development of sense of coherence, and its impact on health through different stages of life.

Open Access This chapter is distributed under the terms of the Creative Commons Attribution-Noncommercial 2.5 License (http:// creativecommons.org/licenses/by-nc/2.5/) which permits any noncommercial use, distribution, and reproduction in any medium, provided the original author(s) and source are credited.

The images or other third party material in this chapter are included in the work's Creative Commons license, unless indicated otherwise in the credit line; if such material is not included in the work's Creative Commons license and the respective action is not permitted by statutory regulation, users will need to obtain permission from the license holder to duplicate, adapt or reproduce the material.

\section{References}

Abraham, A., Sommerhalder, K., \& Abel, T. (2010). Landscape and well-being: A scoping study on the health-promoting impact of outdoor environments. International Journal of Public Health, 55 (1), 59-69.

Angotti, T. (2013). Towards the healthy city: People, places, and the politics of urban planning. Science and Society, 77(4), 595-597.

Aronson, R. E., Norton, B. L., \& Kegler, M. C. (2007). Achieving a "Broad View of Health": Findings from the California healthy cities 
and communities evaluation. Health Education and Behavior, 34 (3), 441-452.

Bai, H., Stanis, S. A. W., Kaczynski, A. T., \& Besenyi, G. M. (2013). Perceptions of neighborhood park quality: Associations with physical activity and body mass index. Annals of Behavioral Medicine, 45(19), 39-48.

Barton, H., \& Grant, M. (2013). Urban planning for healthy cities. A review of the progress of the European healthy cities programme. Journal of Urban Health: Bulletin of the New York Academy of Medicine, 90(Suppl. 1), 129-141.

Boonekamp, G. M. M., Colomer, C., Tomas, A., \& Nunez, A. (1999). Healthy cities evaluation: The co-ordinators perspective. Health Promotion International, 14(2), 103-110.

Bull, T., Mittelmark, M., \& Kanyeka, N. E. (2013). Assets for wellbeing for women living in deep poverty: Through a salutogenic looking-glass. Critical Public Health, 23(2), 160-173.

Cerini, E., Saelens, B. E., Sallis, J. F., \& Frank, L. D. (2006). Neighborhood environment walkability scale: Validity and development of a short form. Medicine and Science in Sports and Exercise, 38(9), $1682-1691$.

Claus, J. M., Dessauer, M., \& Brennan, L. K. (2012). Programs and promotions approaches by 25 active living by design partnerships. American Journal of Preventive Medicine, 43(5), 320-328.

Cohen, D. A., Han, B., Derose, K. P., Williamson, S., Marsh, T., Rudick, J., et al. (2012). Neighborhood poverty, park use, and California city. Social Science and Medicine, 75, 2317-2325.

Cox, M. E., Johnstone, R., \& Robinson, J. (2006). Relationships between perceived coastal waterway condition and social aspects of quality of life. Ecology and Society, 11(1), 35.

de Nazelle, A., Nieuwenhuijsen, M. J., Anto, J. M., Brauer, M., Briggs, D., Braun-Fahrlander, C., et al. (2011). Improving health through policies that promote active travel: A review of evidence to support integrated health impact assessment. Environment International, 37 (4), 766-777.

de Vries, S. I., Bakker, I., van Mechelen, W., \& Hopman-Rock, M. (2007). Determinants of activity-friendly neighborhoods for children: Results from the SPACE study. American Journal of Health Promotion, 21(4), 312-316.

Delmelle, E. C., Haslauer, E., \& Prinz, T. (2013). Social satisfaction, commuting and neighborhoods. Journal of Transport Geography, 30, 110-116.

Donchin, M., Shemesh, A. A., Horowitz, P., \& Daoud, N. (2006). Implementation of the healthy cities' principles and strategies: An evaluation of the Israel healthy cities network. Health Promotion International, 21(4), 266-273.

Dora, C., Pfeiffer, M., \& Racioppi, F. (2013). Lessons from environment and health for HiAP. In K. Leppo, E. Ollila, S. Pena, M. Wismar, \& S. Cook (Eds.), Health in all policies. Seizing opportunities, implementing policies. Helsinki, Finland: Ministry of Social Affairs and Health.

Faskunger, J. (2013). Promoting active living in healthy cities of Europe. Journal of Urban Health: Bulletin of the New York Academy of Medicine Volume, 90(1), 142-153.

Ferney, S. L., Marshall, A. L., Eakin, E. G., \& Owen, N. (2009). Randomized trial of a neighborhood environment-focused physical activity website intervention. Preventive Medicine, 48(2), 144-150.

Frumkin, H. (2003). Healthy places: Exploring the evidence. American Journal of Public Health, 93(9), 1451-1456.

Fuller, B. G., Stewart Williams, J. A., \& Byles, J. E. (2010). Active living. The perception of older people with chronic conditions. Chronic Illness, 6(4), 294-305.

Gidlow, C., Cochrane, T., Davey, R. C., Smith, G., \& Fairburn, J. (2010). Relative importance of physical and social aspects of perceived neighbourhood environment for self-reported health. Preventive Medicine, 51(2), 157-163.
Hand, C., Law, M. C., McColl, M. A., Hanna, S., \& Elliott, S. J. (2012). Neighborhood influences on participation among older adults with chronic health conditions: A scoping review. Occupational Participation and Health, 32(3), 95-103.

Hankey, S., Marshall, J. D., \& Brauer, M. (2012). Health impacts of the built environment: Within-urban variability in physical inactivity, air pollution, and ischemic heart disease mortality. Environmental Health Perspectives, 120(2), 247-253.

Harpham, T., Burton, S., \& Blue, I. (2001). Healthy city projects in developing countries: The first evaluation. Health Promotion International, 16(2), 111-125.

Kaczynski, A. T. (2010). Neighborhood walkability perceptions: Associations with amount of neighborhood-based physical activity by intensity and purpose. Journal of Physical Activity, 7(1), 3-10.

Kegler, M. C., Painter, J. E., Twiss, J. M., Aronson, R., \& Norton, B. L. (2009). Evaluation findings on community participation in the California healthy cities and communities program. Health Promotion International, 24(4), 300-310.

Krenichyn, K. (2004). Women and physical activity in an urban park: Enrichment and support through an ethic of care. Journal of Environmental Psychology, 24(1), 117-130.

Kruize, H., Droomers, M., van Kamp, I., \& Ruijsbroek, A. (2014). What causes environmental inequalities and related health effects? An analysis of evolving concepts. International Journal of Environmental Research and Public Health, 11, 5807-5827.

Kuo, J., Schmitz, K. H., Evenson, K. R., McKenzie, T. L., Jobe, J. B., Rung, A. L., et al. (2009). Physical and social contexts of physical activities among adolescent girls. Journal of Physical Activity and Health, 6(2), 144-152.

Kyttä, M., Broberg, A. K., \& Kahila, M. K. (2012). Urban environment and children's active lifestyle: SoftGIS revealing children's behavioral patterns and meaningful places. American Journal of Health Promotion, 26(5), e137-e148.

Lachowycz, K., \& Jones, A. P. (2013). Towards a better understanding of the relationship between greenspace and health: Development of a theoretical framework. Landscape and Urban Planning, 118, 62-69.

Lenzi, M., Vieno, A., Santinello, M., \& Perkins, D. D. (2013). How neighborhood structural and institutional features can shape neighborhood social connectedness: A multilevel study of adolescent perceptions. American Journal of Community Psychology, 51 (3-4), 451-467.

Levasseur, M., Gauvin, L., Richard, L., Kestens, Y., Daniel, M., \& Payette, H. (2011). Associations between perceived proximity to neighborhood resources, disability, and social participation among community-dwelling adults: Results from the VoisiNuAge Study. Archives of Physical Medicine and Rehabilitation, 92(12), 1979-1986.

Leyden, K. M. (2003). Social capital and the built environment: The importance of walkable neighborhoods. American Journal of Public Health, 93(9), 1546-1551.

Li, F. Z., Fisher, K. J., Brownson, R. C., \& Bosworth, M. (2005). Multilevel modelling of built environment characteristics related to neighbourhood walking activity in older adults. Journal of Epidemiology and Community Health, 59(7), 558-564.

Lindström, B., \& Eriksson, M. (2011). From healthy settings to sustainable healthy societies: The salutogenic approach to planning and health promotion. World Health Design, 4(2), 66-75.

Maass, R., Lindström, B., \& Lillefjell, M. (2014). Exploring the relationships between perceptions of neighbourhood-resources. Sense of coherence and health in different groups in a Norwegian neighbourhood. Journal of Public Health Research, 3(1), 11-20. 
Marmot, M., \& Allen, J. (2013). Prioritizing health equity. In K. Leppo, E. Ollila, S. Pena, M. Wismar, \& S. Cook (Eds.), Health in all policies. Seizing opportunities, implementing policies. Helsinki, Finland: Ministry of Social Affairs and Health.

Marshall, J. D., Brauer, M., \& Frank, L. D. (2009). Healthy neighborhoods: Walkability and air pollution. Environmental Health Perspective, 117(11), 1752-1759.

Millward, H., Spinney, J., \& Scott, D. (2013). Active-transport walking behavior: Destinations, durations, distances. Journal of Transport Geography, 28, 101-110.

Mitchell, R., Astell-Burt, T., \& Richardson, E. A. (2011). A comparison of green space indicators for epidemiological research. Journal of Epidemiology and Community Health, 65(10), 853-858.

Moseley, D., Marzano, M., Chetcuti, J., \& Watts, K. (2013). Green networks for people: Application of a functional approach to support the planning and management of greenspace. Landscape and Urban Planning, 116, 1-12.

Nathan, A., Pereira, G., Foster, S., Hooper, P., Saarloos, D., \& GilesCorti, B. (2012). Access to commercial destinations within the neighbourhood and walking among Australian older adults. International Journal of Behavioral Nutrition and Physical Activity, 9, 133.

Nogueira, H. (2009). Healthy communities: The challenge of social capital in the Lisbon Metropolitan Area. Health and Place, 15(1), $133-139$.

Norgate, S. H. (2012). Accessibility of urban spaces for visually impaired pedestrians. Proceedings of the Institution of Civil Engineers-Municipal Engineers, 165(4), 231-237.

Olilla, E., Baum, F., \& Pena, S. (2013). Introduction to health in all policies and the analytical framework of the book. In K. Leppo, E. Ollila, S. Pena, M. Wismar, \& S. Cook (Eds.), Health in all policies. Seizing opportunities, implementing policies. Helsinki, Finland: Ministry of Social Affairs and Health

Pearson, A. L., Pearce, J., \& Kingham, S. (2013). Deprived yet healthy: Neighborhood-level resilience in New Zealand. Social Science and Medicine, 91, 238-245.

Philips, J., Walford, N., Hockey, A., Foreman, N., \& Lewis, M. (2012). Older people and outdoor environment: Pedestrian anxieties and barriers in the use of familiar and unfamiliar spaces. Geoforum, 47, $113-124$.

Pluemer, K. D., Kennedy, L., \& Trojan, A. (2010). Evaluating the implementation of the WHO Healthy Cities Programme across Germany (1999-2002). Health Promotion International, 25(3), 342-354.

Raerino, K., Macmillan, A. K., \& Jones, R. G. (2013). Indigenous Maori perspectives on urban transport patterns linked to health and wellbeing. Health \& Place, 23, 54-62.

Richard, L., Gauvin, L., Kestens, Y., Shatenstein, B., Payette, H., Daniel, M., et al. (2013). Neighborhood resources and social participation among older adults: results from the VoisiNuage study. Journal of Aging and Health, 25(2), 296-318.

Ries, A. V., Gittelsohn, J., Voorhees, C. C., Roche, K. M., Clifton, K. J., \& Astone, N. M. (2008). The environment and urban adolescents' use of recreational facilities for physical activity: A qualitative study. American Journal of Health Promotion, 23(1), 43-50.

Rychetnik, L., Bauman, A., Laws, R., King, L., Rissel, C., Nutbeam, D., et al. (2012). Translating research for evidence-based public health: Key concepts and future directions. Journal of Epidemiology and Community Health, 66, 1187-1192.

Saelens, B. E., Sallis, J. F., \& Frank, L. D. (2003). Environmental correlates of walking and cycling: Findings from the transportation, urban design, and planning literatures. Annals of Behavioral Medicine, 25(2), 80-91.

Semenza, J. C. (2003). The intersection of urban planning, art, and public health: The sunnyside piazza. American Journal of Public Health, 93(9), 1439-1441.

Semenza, J. C., \& March, T. L. (2009). An urban community-based intervention to advance social interactions. Environment and Behavior, 41(1), 22-42.

Semenza, J. C., March, T. L., \& Bontempo, B. D. (2006). Communityinitiated urban development: An ecological intervention. Journal of Urban Health. Bulletin of the New York Academy of Medicine, 84 (1), 8-20.

Shimura, H., Sugiyama, T., Winkler, E., \& Owen, N. (2012). High neighborhood walkability mitigates declines in middle-to-older aged adults' walking for transport. Journal of Physical Activity and Health, 9(7), 1004-1008.

Ståhl, T., Wismar, M., Ollila, E., Lahtinen, E., \& Leppo, K. (Eds.). (2006). Health in all policies: Prospects and potentials. Helsinki: Ministry of Social Affairs and Health.

Stigsdotter, U. K., Ekholm, O., Schipperijn, J., Toftager, M., KamperJorgensen, F., \& Randrup, T. B. (2010). Health promoting outdoor environments-Associations between green space, and health, health-related quality of life and stress based on a Danish national representative survey. Scandinavian Journal of Public Health, 38 (4), 411-417.

Tartaglia, S. (2013). Different predictors of quality of life in urban environment. Social Indicators Research, 113, 1045-1053.

Twiss, J., Dickinson, J., Duma, S., Kleinman, T., Paulsen, H., \& Rilveria, L. (2003). Community gardens: Lessons learned from California healthy cities and communities. American Journal of Public Health, 93(9), 1435-1438.

Wen, L. M., Kite, J., Merom, D., \& Rissel, C. (2009). Time spent playing outdoors after school and its relationship with independent mobility: A cross-sectional survey of children aged 10-12 years in Sydney, Australia. International Journal of Behavioral Nutrition and Physical Activity, 6, 15.

WHO. (2007). Our cities, our health, our future: Acting on social determinants for health equity in urban settings. Kobe, Japan: Report to the WHO Commission on Social Determinants of Health from the Knowledge Network Urban Settings.

WHO. (2012a). Addressing the social determinants of health: The urban dimension and the role of local government. London, UK: WHO, Institute of Health Equity, University College London.

WHO. (2012b). Environmental Health Inequalities in Europe. Assessment report. Bonn, Germany: World Health Organisation.

Williams, A., \& Kitchen, P. (2012). Sense of place and health in Hamilton, Ontario: A case-study. Social Indicators Research, 108 (2), 257-276.

Wilson, L. M., Giles-Corti, B., Burton, N. W., Giskes, K., Haynes, M., \& Turrell, G. (2011). The association between objectively measured neighborhood features and walking in middle-aged adults. American Journal of Health Promotion, 25(4), 12-21.

Winkler, M. S., Krieger, G. R., Divall, M. J., Cisse, G., Wielga, M., Singer, B. H., et al. (2013). Untapped potential of health impact assessment. Bulletin of the World Health Organisation, 91, 298-305.

World Health Organisation (WHO). (1986). The Ottawa-charter for Health Promotion. Ottawa: 1986. Retrieved from http://www.who. int/healthpromotion/conferences/previous/ottawa/en/ 